\title{
Front Matter: Volume 10176
}

, "Front Matter: Volume 10176," Proc. SPIE 10176, Asia-Pacific Conference on Fundamental Problems of Opto- and Microelectronics, 1017601 (19 May 2017); doi: 10.1117/12.2269235

SDIE Event: Asia-Pacific Conference on Fundamental Problems of Opto- and Microelectronics, 2016, Khabarovsk, Russia 


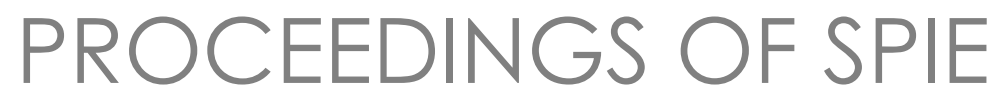

\title{
Asia-Pacific Conference on Fundamental Problems of Opto- and Microelectronics
}

\author{
Yuri N. Kulchin \\ Roman V. Romashko \\ Alexander V. Syuy \\ Editors
}

11-13 October 2016

Khabarovsk, Russian Federation

Organized by

Institute of Automation and Control Processes, Far-Eastern Branch of Russian Academy of Sciences (Russian Federation)

Far-Eastern State Transport University (Russian Federation)

Sponsored by

Russian Foundation for Basic Research (Russian Federation)

Ministry of Education and Science of Khabarovsk Region (Russian Federation)

Published by

SPIE

Volume 10176 
The papers in this volume were part of the technical conference cited on the cover and title page. Papers were selected and subject to review by the editors and conference program committee. Some conference presentations may not be available for publication. Additional papers and presentation recordings may be available online in the SPIE Digital Library at SPIEDigitallibrary.org.

The papers reflect the work and thoughts of the authors and are published herein as submitted. The publisher is not responsible for the validity of the information or for any outcomes resulting from reliance thereon.

Please use the following format to cite material from these proceedings:

Author(s), "Title of Paper," in Asia-Pacific Conference on Fundamental Problems of Opto- and Microelectronics, edited by Yuri N. Kulchin, Roman V. Romashko, Alexander V. Syuy, Proceedings of SPIE Vol. 10176 (SPIE, Bellingham, WA, 2016) Seven-digit Article CID Number.

ISSN: 0277-786X

ISSN: 1996-756X (electronic)

ISBN: 9781510608535

ISBN: 9781510608542 (electronic)

Published by

SPIE

P.O. Box 10, Bellingham, Washington 98227-0010 USA

Telephone +1 3606763290 (Pacific Time) · Fax +1 3606471445

SPIE.org

Copyright (c) 2016, Society of Photo-Optical Instrumentation Engineers.

Copying of material in this book for internal or personal use, or for the internal or personal use of specific clients, beyond the fair use provisions granted by the U.S. Copyright Law is authorized by SPIE subject to payment of copying fees. The Transactional Reporting Service base fee for this volume is $\$ 18.00$ per article (or portion thereof), which should be paid directly to the Copyright Clearance Center (CCC), 222 Rosewood Drive, Danvers, MA 01923. Payment may also be made electronically through CCC Online at copyright.com. Other copying for republication, resale,

advertising or promotion, or any form of systematic or multiple reproduction of any material in this book is prohibited except with permission in writing from the publisher. The CCC fee code is 0277-786X/16/\$18.00.

Printed in the United States of America.

Publication of record for individual papers is online in the SPIE Digital Library.

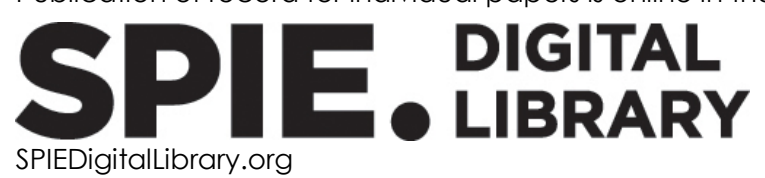

Paper Numbering: Proceedings of SPIE follow an e-First publication model. A unique citation identifier (CID) number is assigned to each article at the time of publication. Utilization of CIDs allows articles to be fully citable as soon as they are published online, and connects the same identifier to all online and print versions of the publication. SPIE uses a seven-digit CID article numbering system structured as follows:

- The first five digits correspond to the SPIE volume number.

- The last two digits indicate publication order within the volume using a Base 36 numbering system employing both numerals and letters. These two-number sets start with $00,01,02,03,04$, 05, 06, 07, 08, 09, OA, OB ... 0Z, followed by 10-1Z, 20-2Z, etc. The CID Number appears on each page of the manuscript. 


\title{
Contents
}

\author{
ix Authors \\ xi Conference Committee \\ $\mathrm{xV}$ Introduction
}

\section{ASIA-PACIFIC CONFERENCE ON FUNDAMENTAL PROBLEMS OF OPTO- AND} MICROELECTRONICS

1017602 Excitons and low-threshold optical nonlinearity of dielectric nanosystems [10176-41]

1017603 Optical absorption by excitons of quasi-zero dielectric quantum dot [10176-46]

$1017604 \mathbf{M g}_{2} \mathrm{Si}_{\mathbf{x}} \mathrm{Sn}_{1-x}$ heterostructures on $\mathrm{Si}(111)$ substrate for optoelectronics and thermoelectronics [10176-59]

1017605 Formation of bistable medium state in nanofluids under the influence of laser radiation [10176-69]

1017606 Ultraviolet and EELS spectra of $\mathrm{CeO}_{2}$ nanoparticles produced by laser ablation [10176-73]

1017607 Light induced lens response in nanosuspension [10176-66]

1017608 Optical methods in diagnostics of liver fibrosis via blood observation [10176-10]

1017609 Study on thin wideband applicator for detecting blood characteristics in human body [10176-75]

10176 OA Monte Carlo simulation of Raman confocal spectroscopy of beta-carotene solution [10176-67]

10176 OB Crystallography method for protein solutions photomodification study [10176-22]

10176 OC Protein solution photomodification analysis by means of craquelure structures [10176-29]

10176 OD Laser activation of a nutrient medium and antibiotic solutions and its estimation by of bacteria growth dynamics [10176-27]

$10176 \mathrm{OE}$ Local heating in biological body using wireless transmission power into small resonant devices driven by MRI [10176-76]

10176 OF Numerical simulation studies for optical properties of biomaterials [10176-78]

10176 OG Efficiency of use endobronchial laser Doppler-flowmetry in patients with chronic leukemia [10176-72] 
$10176 \mathrm{OH} \quad$ A database of biominerals with optical properties founded in living organisms [10176-60]

$10176 \mathrm{Ol}$ Formation of the reflected and refracted s-polarized electromagnetic waves in the Fresnel problem for the boundary vacuum-metamaterial from the viewpoint of molecular optics [10176-50]

$101760 \mathrm{~J}$ Experimental verification of surface plasmon resonance excitation in bent single-mode optical fibers using whispering gallery modes [10176-54]

10176 OK Numeric simulation of RF modulated optical pulses propagation in photonic time-stretch system [10176-18]

$10176 \mathrm{OL} \quad$ Hollow core Bragg fiber with antiresonant intermediate layer [10176-36]

$10176 \mathrm{OM} \quad \mathrm{Hydrothermal} \mathrm{synthesis}$ of $\mathrm{TiO}_{2} / \mathrm{WO}_{3}$ compositions and their photocatalytic activity [10176-79]

10176 ON Complex research of the particles which cause air pollution by laser granulometry, Raman-spectrometry and IR-spectrometry [10176-37]

1017600 Formation of surface plasmon polaritons by silver nano-strip and nano-circle [10176-31]

10176 OP Simulation of internal charge distribution and spatial charge characteristics of ferroelectrics irradiated by focused electron beam [10176-28]

$101760 Q \quad$ Interaction of moving domain walls with constant magnetic fields in iron borate and yttrium orthoferrite single crystals [10176-33]

10176 OR New data about optic properties of biominerals from some brown algae Undaria pinnatifida and Laminaria japonica [10176-51]

10176 OS Laser generation of ultrasound and ultrasound velocity measurements in glasses [10176-38]

10176 OT Measurement of an ambient air leak by diode laser absorption spectroscopy [10176-65]

10176 OU Accelerating space-charge gratings in wide-bandgap semiconductors as a tool for simultaneous velocity and acceleration measurement [10176-70]

10176 OV Diagnostics of nanosuspension by the light-induced pseudo-prism method [10176-58]

10176 OW Fiber optic seismometers for weak seismic signals registration [10176-68]

10176 OX Novel UV probe for selective detection of Au and Pd in aqueous solutions [10176-8]

10176 OY Dynamic measurement of temperature dependent permittivity and permeability by microwave irradiation [10176-74]

$101760 Z$ A testing method for the machine details state by means of the speckle image parameters analysis [10176-30]

1017610 Luminescent chemosensors for amines and ammonia based on Eu(III) chelate complexes [10176-6] 
1017611 The laser radiation action on the crystal formation processes in the biological fluids [10176-17]

1017612 Detecting weak acoustic fields by multichannel fiber optical sensory system [10176-3]

1017613 Detection of acoustic emission signals in the polymer composite material by adaptive fiber optic sensors [10176-35]

1017614 Fiber optic hydrophone based on adaptive holographic interferometer [10176-2]

1017615 Aerosol retrievals with multi-wavelength raman lidar at IACP Lidar station [10176-45]

1017616 Highly sensitive two-channel laser acoustic sensor [10176-4]

1017617 High spatial resolution absorption contrast imaging with electron-beam excitation assisted optical microscope [10176-64]

1017618 Photonic sampled ADC's: state of the art [10176-13]

1017619 Optical encryption of digital data in form of quick response code using spatially incoherent illumination [10176-15]

10176 1A Object recognition in non-coherent optical correlator based on DMD-modulator [10176-24]

10176 1B Image segmentation algorithm in the system focusing digital camera [10176-48]

10176 1C Azimuthal polarizer with phase shift for subwavelength focusing of laser light [10176-77]

10176 ID Informatics and computational method for inundation and land use study in Arctic Sea eastern Siberia, Russia [10176-19]

$10176 \mathrm{lE}$ Studying of welding aerosol using laser granulometry [10176-40]

$10176 \mathrm{IF}$ Acoustic emission and magnification of atomic lines intensity originated by laser breakdown of salt water [10176-25]

10176 1G Electro-optic modulation of broadband radiation for the infrared spectral range [10176-43]

$10176 \mathrm{H} \mathrm{Laser} \mathrm{excitation} \mathrm{of} \mathrm{transversal} \mathrm{and} \mathrm{longitudinal} \mathrm{polar} \mathrm{modes} \mathrm{in} \mathrm{lithium} \mathrm{niobate} \mathrm{and}$ tantalate crystals [10176-23]

1017611 Collinear and vector interaction of light waves in nonlinear optical crystals $\mathrm{KT}_{i} \mathrm{OPO}_{4}($ (KTP"), $\mathrm{Ba}_{2} \mathrm{NaNb}_{5} \mathrm{O}_{15}$ ("banana") [10176-49]

$101761 \mathrm{~J} \mathrm{Conversion} \mathrm{of} \mathrm{broadband} \mathrm{IR} \mathrm{radiation} \mathrm{and} \mathrm{structural} \mathrm{disorder} \mathrm{in} \mathrm{lithium} \mathrm{niobate} \mathrm{single}$ crystals with low photorefractive effect [10176-62]

10176 1K Effect of preparation conditions of calcium bismuthate based photocatalyst on its catalytic properties [10176-9] 
10176 IL Application of pyrolitic method of synthesis for preparation of calcium bismuthate based photocatalyst [10176-11]

$101761 \mathrm{M}$ Optical radiation characteristics that affect the formation of large-scale and small-scale optical defects in photorefractive crystals [10176-52]

10176 iN Determination of electro-optic coefficients of lithium niobate crystal by polarization and interference methods [10176-39]

1017610 Structure disorder and photorefractive properties of $\mathrm{LiNbO}_{3}: \mathrm{Zn}$ crystals [10176-21]

10176 IP Structure disorder and photorefractive properties of LiNbO $3: B$ crystals [10176-14]

$101761 Q$ Secondary structure and optical properties of ferroelectric lithium niobate crystals [10176-26]

10176 IR The laser conoscopy of lithium niobate crystals of different composition [10176-16]

10176 is Light beams interaction with highly effective holographic diffraction structure formed in polymer-stabilized liquid crystal under the impact of arbitrarily spatially inhomogeneous electric field [10176-5]

10176 IT Formation and readout of holographic amplitude and phase non-uniform polarization gratings in polymer-stabilized liquid crystals [10176-20]

$101761 \mathrm{U}$ Orthogonal three-wave mixing in InP crystal [10176-1]

$101761 \mathrm{~V}$ Simulation of nonlinear effects at laser modification of the surface minerals with gold [10176-71]

10176 1W Mechanism of luminescence from porous silicon [10176-34]

10176 1X Light induced mechanism of the bubble clusters formation [10176-63]

$10176 \mathrm{IY}$ Features of extraordinary ray propagation in an optically anisotropic birefringent prism [10176-42]

1017612 Transient gratings in the transparent nanoliquid [10176-61]

1017620 Direct laser welding of Sm and Fe powders for creation of magnetic alloys on the stainless steel substrate: microstructure and magnetic properties [10176-53]

1017621 Structure and magnetic properties of alloys formed by the laser welding of Sm and Co powders on different substrates [10176-47]

1017622 An influence of formation methods of laser layer's welding on their phase composition and magnetic properties [10176-55]

1017623 Magnetic properties of laser welded coatings from Sm and Fe powders with and without magnetic field on Al based substrate [10176-56] 
1017624 Optimization of the fiber laser parameters for local high-temperature impact on metal [10176-44]

1017625 Photoelectric element on the basis of the sandwich metal-ferroelectric-metal structure [10176-57]

1017626 Light fields generated by LC focusing device in different operational regimes [10176-32] 
Proc. of SPIE Vol. 10176 1017601-8

Downloaded From: https://www.spiedigitallibrary.org/conference-proceedings-of-spie on 26 Apr 2023 Terms of Use: https://www.spiedigitallibrary.org/terms-of-use 


\section{Authors}

Numbers in the index correspond to the last two digits of the seven-digit citation identifier (CID) article numbering system used in Proceedings of SPIE. The first five digits reflect the volume number. Base 36 numbering is employed for the last two digits and indicates the order of articles within the volume. Numbers start with 00, 01, 02, 03, 04, 05, 06, 07, 08, 09, 0A, 0B...0Z, followed by 10-1Z, 20-2Z, etc.

Adamova, Maria E., $\mathrm{OQ}$

Amosov, A. V., 02, 03

Asalkhanova, Mariya A., $1 \mathrm{U}$

Atuchin, Victor $V ., 08$

Averbukh, B. B., Ol

Averbukh, I. B., 0 l

Bamba, Kazuki, 09

Bashkov, Oleg V., 13

Bazylev, P. V., OS

Bezruk, Michail N., 12, 13, 14

Blokh, Artem I., 1K, $1 \mathrm{~L}$

Bobrikov, Alexey A., 15

Boori, Mukesh Singh, ID

Bratskaya, S., OX

Bryushinin, Mikhail, oU

Bulanov, A. V., IF

Burkov, Alexander A., OM

Cheremkhin, Pavel A., 19

Cherepakhin, Artem B., OJ

Chernev, Igor M., 04

Chernyshov, Alexander, OT

Choudhary, Komal, ID

Chung, G., OR

Cora, I., 04

Deinekina, N. A., 11

Dotsenko, Sergey A., 04

Dózsa, L., 04

Drozd, V. A., $1 \mathrm{E}$

Dudko, Olga $\vee ., 24$

Dyshlyuk, Anton $V_{\text {., }} 0 \mathrm{~J}$

Dzyuba, V. P., 02, 03

Efimov, Timofey A., 16

Emelina, Tatiana B., 10

Ermolaev, Sergey A., 12, 14

Faleev, D. S., 11

Fukuta, Masahiro, 17

Gabain, Aleksei A., $1 \mathrm{~J}$

Galkin, Konstantin N., 04

Galkin, Nickolay G., 04, 1W, 20, 21, 22, 23

Generalov, Vladimir M., 08

Golokhvast, Kirill S., OH, ON, OR, 1E

Goncharova, P. S., IG

Gorelik, Vladimir S., $1 \mathrm{H}$

Gridasov, A. V., 1E

Gromov, Andrey A., 08

Gutnikov, Sergei A., OH, OR

Htoo, Han, 13

Inami, Wataru, 17

Ivanov, Valery I., 07, 0V, 1X, 1Z, 25
Ivanova, Galina D., 07, 0V, 1X, 1 Z

Kamenev, Oleg T., OW

Kaminsky, Aleksandr $\mathrm{V} ., \mathrm{OQ}$

Karpets, Yury M., 05, 1X, 25

Karpovich, Natalia F., OM

Kawata, Yoshimasa, 17

Khamitova, Alexandra Sh., OB

Khe, Vladimir K., 07, OV

Kholodov, A. S., ON

Kile, E. O., $1 \mathrm{~N}$

Kireeva, N. M., 05

Kirichenko, K. YU., $1 \mathrm{E}$

Kiseleva, Natalia O., OB

Kokorina, Lubov A., OD

Komina, Olga Yu., OQ

Korosteleva, I. A., 11

Kostyanko, Artem A., 20, 21

Kotlyar, Maria V., 1C

Kotlyar, Victor V., 00, $1 \mathrm{C}$

Kotova, Svetlana P., 26

Kozlova, Elena S., 00

Krasnikov, I., OA, OF

Krasnov, Vitaly $V_{.,} 19$

Kravchenko, O. V., 11

Krishtop, Victor V., 05, 1G, 1J, 1M

Kruchinin, Vladimir N., 08

Kruchinina, Margarita $V_{\text {., }} 08$

Krumgolts, I. Ya., OS

Krylov, Vladimir I., OV

Kudrawiec, R., 04

Kuki, Takao, 09

Kulchin, Yuri N., 02, 03, 0J, OL, OW, 10, 12, 14, 16,

$1 \mathrm{U}, 20,21,22,23$

Kupriyanov, Alexander, ID

Kuzin, Andrey A., $1 \mathrm{X}$

Landyshev, Y.S., OG

Leonenko, N. A., $1 \mathrm{~V}$

Leonov, Andrei A., 10

Litvinov, Vladimir A., $1 \mathrm{~J}$

Litvinova, Man Nen, $1 \mathrm{~J}$

Livashvili, A. I., 05

Lugovoy, V. A., OS

Makarevich, Konstantin S., OM, $1 \mathrm{~L}$

Maksimenko, Vitaliy A., 1M

Malov, Alexander N., OB, OC, OD, 0Z, 11

Maslov, Andrei M., 04

Maslovskaya, Anna G., OP

Mayorova, Aleksandra M., 26

Meinhardt-Wollweber, M., OA 
Migas, D. B., 04

Mikheyev, Pavel A., OT

Mirochnik, Anatolii G., 10

Mironenko, A., OX

Misiewicz, J., 04

Mitsai, Evgeniy $\vee ., 0 \mathrm{~J}$

Molodtsov, D. YU, IA

Morozov, Alexey N., OC

Myagotin, Artyom V., $1 \mathrm{Z}$

Nagorny, I. G., IF

Nakano, Akitsugu, OE

Nalimov, Anton G., $1 C$

Nebavskiy, V. A., OK

Neupokoeva, Anna $\vee .$, OB, OC, OD, OZ

Nikawa, Yoshio, 09, 0E, OY

Nikitin, Aleksander I., 20, 21, 22, 23

Novikova, Evgeniya A., 11

O'Faolain, Liam, $1 \mathrm{C}$

Osváth, Z., 04

Palatnikov, Mikhail N., 1J, 10, 1P, 1Q, 1R

Pamirsky, Igor $\mathrm{E}$., $\mathrm{OH}, \mathrm{OR}$

Panov, Andrey V., OL

Pavelchuk, Anna V., OP

Pavlov, Andrey N., 15

Pavlov, Pavel V., OZ

Pécz, B., 04

Perkov, Yury O., 25

Petrochenkova, Nataliya $\vee ., 10$

Petrov, Yuriy S., OW

Pikoul, O. Y., IR

Pivovarov, D. C., 20

Pogodina, Veronika A., $1 \mathrm{~J}$

Pokutnyi, S. I., 03

Polonik, Marina V., 24

Ponomarchuk, Yulia V., $1 \mathrm{~J}$

Popov, Fedor N., OZ

Protsenko, Alexander E., 13

Pugachevskii, M. A., 06

Pyachin, Sergey A., OM

Rodin, Vladislav G., 19, 1 A

Romashko, Roman V., 12, 13, 14, 16, $1 \mathrm{U}$

Roth, B., OA

Rykhlitsky, Sergey V., 08

Sai, Sergey $\vee ., 1 B$

Samagin, Sergey A., 26

Semkin, Artem O., 1S, $1 T$

Sergeev, Alexander A., OX, 10

Seteikin, A., OA, OF

Sharangovich, Sergey N., 1S, IT

Shishov, Alexander S., 10

Shmirko, Konstantin A., 15

Shtarev, Dmitry S., 1K, $1 \mathrm{~L}$

Shtareva, Anna V., 1K, $1 \mathrm{~L}$

Sidorov, Nikolay $V_{\text {., }} 1 \mathrm{H}, 1 \mathrm{~J}, 1 \mathrm{O}, 1 \mathrm{P}, 1 \mathrm{Q}, 1 \mathrm{R}$

Simonova, Elena $V_{\text {., OD }}$

Sokolov, Igor, OU

Stafeev, Sergey S., 1C

Starikov, Rostislav S., OK, 18, 19

Stebliy, Maxim E., 21, 22, 23

Stolyarchuk, Sergey Yu., 15
Storozhenko, Dmitry A., 12

Subbotin, Evgeniy P., 20, 21, 22, 23

Sugimoto, Atsuko, ID

Sverbil, Pavel P., $1 \mathrm{H}$

Syuy, Alexander V., 1G, 1J, 1K, 1L, 1N

Teplyakova, Natalya A., 10, 1P, 1R

Terakawa, Susumu, 17

Timoshenko, Elena A., OC

Titov, Roman A., 10, $1 \mathrm{P}$

Tkacheva, S. I., OG

Tutov, M., OX

Ustinov, Alexander Yu., OM

Vaichas, Andrey A., 11

Vanina, E. A., 0G, IV

Veselova, E. M., IV

Vitrik, Oleg B., OJ

Vodchits, Alexander I., $1 \mathrm{H}$

Voitsekhovskiy, V. V., OG

Volodin, Vladimir A., 08

Voznesenskiy, Sergey S., 10

Yan, Dmitry, IW

Yanichev, Alexander A., 10, $1 \mathrm{P}$

Yatsko, Dmitriy S., 20, 21, 22, 23, 24

Zaitsev, Alexey V., OM

Zaykov, Valeriy I., 13

Zhukov, Evgenij A., OQ

Zhukova, Valentina I., $0 Q$

Zinin, Yurii A., OL

Zisser, laroslav, $1 Y$

Zisser, Irina, IY

Zlokazov, E. Yu., OK 


\title{
Conference Committee
}

\author{
Conference Chair
}

Yuri N. Kulchin, Institute of Automation and Control Processes, Far-Eastern Branch of Russian Academy of Sciences (Russian Federation)

\section{Program Committee}

Yuri N. Kulchin, Institute of Automation and Control Processes, Far-Eastern Branch of Russian Academy of Sciences (Russian Federation)

Oleg N. Krokhin, Lebedev Physical Institute, Russian Academy of Sciences, (Russian Federation)

Yoshio Nikawa, Kangnam University (Korea, Republic of)

Viktor V. Krishtop, Far-Eastern State Transport University (Russian Federation)

Jingping Ou, Dalian University of Technology (China)

Alexandr A. Gorbatsevich, Moscow Institute of Electronic Technology (Russian Federation)

Youngdo Joo, Kangnam University (Korea, Republic of)

Andrei V. Kabashin, Le Centre National de la Recherche Scientifique (France)

Alexei A. Kamshilin, ITMO University (Russian Federation)

Svetlana P. Kotova, Lebedev Physical Institute, Samara Branch (Russian Federation)

Makoto Kozaki, Kokushikan University (Japan)

Sridhar Krishnaswamy, Northwestern University (United States)

Junqing Li, Harbin Institute of Technology (China)

Ikai Lo, Sun Yat-sen University (Taiwan)

Guohui Lv, Heilongjiang University (China)

Vladimir A. Makarov, M.V. Lomonosov Moscow State University (Russian Federation)

Alexandr N. Malov, Irkutsk State University (Russian Federation)

Vladimir Ya. Panchenko, Institute on Laser and Information Technologies of the Russian Academy of Sciences (Russian Federation)

Roman V. Romashko, Institute for Automation and Control Processes of the Russian Academy of Sciences (Russian Federation)

Oleg V. Rudenko, M.V. Lomonosov Moscow State University (Russian Federation)

Marc Sentis, Centre National de la Recherche Scientifique (France) 
Stanislav M. Shandarov, Tomsk State University of Control Systems and Radioelectronics (Russian Federation)

Vasily V. Shepelevich, Mozyr State Pedagogical University named after I.P. Shamyakin (Belarus)

Alexandr V. Syuy, Far-Eastern State Transport University (Russian Federation)

S. Shon, Suwon University (Korea, Republic of)

X. D. Sun, Harbin Institute of Technology (China)

Oleg B. Vitrik, Institute of Automation and Control Processes,

Far- Eastern Branch of Russian Academy of Sciences (Russian Federation)

Leonid P. Yatsenko, Institute of Physics of the National Academy of Sciences (Ukraine)

Irina N. Zavestovskaya, Lebedev Physical Institute, Russian Academy of Sciences (Russian Federation)

Alexei M. Zheltikov, M.V. Lomonosov Moscow State University (Russian Federation)

Irina A. Zhurbina, Russian Foundation for Basic Research (Russian Federation)

Zhi Zhou, Dalian University of Technology (China)

Advisory Committee

Toshihiro Shimizu, Kokushikan University (Japan)

Seungho Cho, Kangnam University (Korea, Republic of)

Nikolai N. Evtikhiev, Moscow Engineering Physics Institute

(Russian Federation)

Session Chairs

1 New Materials and Structures for Photonics I

Yoshio Nikawa, Kangnam University (Korea, Republic of)

2 Micro- and Nanotechnologies for Optoelectronics

Viktor V. Krishtop, Far-Eastern State Transport University (Russian Federation)

3 Informatics and Computational Methods in Photonics

Der-Jang Liaw, National Taiwan University of Science and Technology (Taiwan)

$4 \quad$ New Materials and Structures for Photonics II

Rostislav S. Starikov, Moscow Engineering Physics Institute (Russian Federation) 
5 Optical and Photonics Systems for Acoustics

Oleg B. Vitrik, Institute of Automation and Control Processes,

Far-Eastern Branch of Russian Academy of Sciences

(Russian Federation)

6 Optoelectronics for Life Sciences

Makoto Kozaki, Kokushikan University (Japan)

$7 \quad$ New Materials and Structures for Photonics III

Alexandr V. Syuy, Far-Eastern State Transport University

(Russian Federation)

$8 \quad$ Nonlinear Optics

Roman V. Romashko, Institute of Automation and Control Processes,

Far-Eastern Branch of Russian Academy of Sciences

(Russian Federation)

9 Optoelectronic Sensory and Measurement Systems

Alexei Yu. Seteikin, Amur State University (Russian Federation) 
Proc. of SPIE Vol. 10176 1017601-14 Downloaded From: https://www.spiedigitallibrary.org/conference-proceedings-of-spie on 26 Apr 2023
Terms of Use: https://www.spiedigitallibrary.org/terms-of-use 


\section{Introduction}

The 15th Asia-Pacific Conference on Fundamental Problems of Opto- and Microelectronics (APCOM 2016) was held in the far east of the Russia Federation in October 2016. Since 2000, the conference has been the venue for cutting-edge achievements in a variety of topics related to opto- and microelectronics. During the intervening years, the focus of the conference has shifted to fundamental and applied aspects of optics, photonics and nano-electronics and covers photonic communication, optical measuring systems, photonic sensors, as well as their application in life-sciences, bio-medicine, social welfare, industrial facilities, and structural health monitoring. The conference also covers novel materials and structures for optics and photonics, new principles and methods for optical information processing and imaging, and nano- and bio-photonics.

In the past, APCOM papers have been published as SPIE Proceedings (volumes $4513,4357,5129,5851$, and 6595); and now, with the publication of this SPIE volume, we are glad to have restored the long-established tradition.

We are looking forward to receiving submissions for the 16th APCOM conference in 2017.

Yuri N. Kulchin

SPIE Fellow 
Proc. of SPIE Vol. 10176 1017601-16 Downloaded From: https://www.spiedigitallibrary.org/conference-proceedings-of-spie on 26 Apr 2023
Terms of Use: https://www.spiedigitallibrary.org/terms-of-use 